\title{
ACCESS TO HANDHYGIENE IN SOUTH EAST ASIA IN RELATION TO COVID-19: A REVIEW
}

\author{
IMTEYAZ AHMED*, AJAZ WANI A
}

Department of Zoology, Government Degree College, Doda, Jammu and Kashmir. Email: imteyaz999ahmed@gmail.com

Received: 18 September 2020, Revised and Accepted: 25 December 2020

\begin{abstract}
The present review aims at gathering refocus on access to handwashing in South East Asia. It is because, here nearly half of the households, schools and about one fourth of the health care centers lack the basic handwashing facility and that too at the time when about one third of global new COVID-19 positive cases are getting reported from this region these days. Data on access to, handwashing device having soap and water availability, in South Asia is mainly based on the World Health Organization (WHO) and United Nations Children's Fund (UNICEF JMP) Joint Monitoring Programme for Water Supply, Sanitation, and Hygiene (WHO/UNICEF JMP 2020). In addition various relevant research and review papers were reviewed using the key words such as handwashing, South East Asia, Hand hygiene, and COVID-19. There is a high need to reaccess the factor of hand hygiene in South East Asia in relation to COVID-19 for the control of the present pandemic and other such challenges, particularly in South East Asia
\end{abstract}

Keywords: Handwashing, SARS CoV-2, Soap and water, Sanitation.

\section{INTRODUCTION}

COVID-19 is a highly contagious disease [1]. It is caused by SARS CoV-2 [2]. COVID-19 produces symptoms such as fever (not in all), cough, throat infection, headache, and breathlessness. Conjunctivitis has also been found. These symptoms look similar to other respiratory infections. In some cases, the disease may progress to severe pneumonia, followed by respiratory failure and death within a week [3]. COVID-19 is transmitted by two dominant routes, that is, respiratory and poor hygiene. Interperson transmission occurs mainly through droplet splashing when there is a gap of less than a meter in between. Transmission is also possible by contact with an infected person without using personal protective equipment (PPE) [4-7].

Research shows that SARS-CoV-2 is more stable on plastics and stainless steel than copper and cardboard. Viruses have been found on these steel and plastic surfaces even after $72 \mathrm{~h}$ [8]. This persistent virus reaches to the hands of touching person and then through the agency of hands to his/her eyes, nose, and mouth [9-11]. The World Health Organization (WHO) recommends washing hands with soap to prevent COVID-19 infection because washing hands with soap prevents transmission of COVID-19 along with other infectious diseases such as diarrhea and pneumonia [12]. Further, hand hygiene is essential for disease control in different settings such as commercial, domestic food preparation, in health care, day care, educational, and occupational institutions [13-15].

Handwashing with soap has been found to reduce the risk of diarrhea episodes by $30-47 \%$ and respiratory infections by $23 \%$. The presence of a fixed handwashing place facilitated with water and soap, is a feasibly collected measure to describe handwashing behavior in large, nationally representative household surveys such as Multiple Indicator Cluster Survey or Demographic and Health Survey [16]. A very significant hygienic behavior for health is handwashing with soap and water. It is a top priority in different settings. The availability of a basic handwashing facility is a prerequisite for basic hygiene facilities on premises and is a useful proxy for hygienic behavior [17]. At present, humankind is challenged with a serious threat from the novel coronavirus (SARS-CoV-2) pandemic [18]. Handwashing has been considered as an important strategy for prevention of its transmission in households and communities.

Handwashing requires safe water that does not represent any significant risk to health over a lifetime of consumption, and that is free of microbial pathogens, chemicals and radiological substances.
The human right to safe water is fundamental for dignified life. Yet approximately 844 million people live without access to safe water worldwide. A good number of around 110 million such people live in Southeast Asia [19].

The present review aims that during an infectious disease outbreak such as COVID-19, an effective emergency response should be a focus on providing rapid, low-cost water service provision for communities, health care facilities, and schools that lack a reliable and safe supply. Moreover, as fixed and portable handwashing facilities, soap and alcohol-based hand rubs, and water supplies are secured, educational and behavioral tools, and tactics can help people understand that handwashing can be the difference between life and death [20].

\section{METHODOLOGY}

Data on access to handwashing facility having soap and water availability are based on the WHO and United Nations Children's Fund Joint Monitoring Programme (UNICEF JMP) for Water Supply, Sanitation and Hygiene (WHO/UNICEF JMP 2020) [21]. The data of different South East Asian Countries on COVID-19 have been taken from the WHO website. Furthermore, various relevant research and review papers were searched using the key words such as handwashing, South East Asia, hand hygiene, and COVID-19 for the preparation of this review article.

\section{HANDWASHING IN SOUTH EAST ASIA AND COVID-19 PANDEMIC}

In WHO Region of South East Asia, washing hands with soap and water receives too low a priority at homes and in schools despite the availability of basic water services to many people there. 796 million people here do not have basic handwashing facilities with soap and water at home. In India alone, there are 542 million such people. More than half of the schools in Indonesia and Bangladesh do not have facilities for washing hands with soap and water. There are large disparities in the availability of handwashing facilities at home between the poorest and richest in South-East Asia. Handwashing facilities with soap and water are more prevalent in urban than in rural areas of South-East Asia [22,23].

If we consider the COVID-19 situation in South East Asia, as per WHO, there are 35,33,807 cumulative positive cases on $23^{\text {rd }}$ of August, 2020 (Table 1), which are around $16 \%$ of the total global number (Table 2). It is really very important to mention here that about $31 \%$ of the total new global COVID-19 cases are getting added in WHO Region 
Table 1: COVID-19 data in South East Asia on 23-08-2020

\begin{tabular}{lllll}
\hline S. No. & Country/Region & $\begin{array}{l}\text { New cases on } \\
\mathbf{2 3 - 0 8 - 2 0 2 0}\end{array}$ & $\begin{array}{l}\text { Cumulative cases on } \\
\mathbf{2 3 - 0 8 - 2 0 2 0}\end{array}$ & $\begin{array}{l}\text { New deaths on } \\
\mathbf{2 3 - 0 8 - 2 0 2 0}\end{array}$ \\
\hline 1 & & 69239 & 3044940 & 912 \\
$\mathbf{2 3 - 0 8 - 2 0 2 0}$
\end{tabular}

Table 2: Global percent of COVID-19 data in South East Asia on 23-08-2020

\begin{tabular}{lllll}
\hline S. No. & Regional/Global & $\begin{array}{l}\text { New cases on } \\
\mathbf{2 3 - 0 8 - 2 0 2 0}\end{array}$ & $\begin{array}{l}\text { Cumulative cases } \\
\text { on 23-08-2020 }\end{array}$ & $\begin{array}{l}\text { New deaths on } \\
\mathbf{2 3 - 0 8 - 2 0 2 0}\end{array}$ \\
\hline 1 & & 74,368 & $35,33,807$ & 1063 \\
2 & $2,44,223$ & $2,30,57,288$ & 5772 \\
3 & South East Asia & $30.45 \%$ & $16 \%$ & $18.41 \%$ \\
\hline
\end{tabular}

of South East Asia these days. Nearly one third of total new global cases coming in this region is quite alarming and requires immediate attention. Furthermore, about 19\% of global deaths due to COVID-19 are happening in this region. There is a huge probability of increase in these figures in the coming days.

India alone records about 70,000 new COVID-19 positive cases per day these days, which being a huge number.

Personal hygiene and more specifically handwashing practices have come under reconsideration as there are millions of souls in South East Asia, not having their reach to the very basic needs of life like water. COVID-19 pandemic has brought the issue of handwashing to the forefront as hand hygiene ignorance being an easiest mode for both catching and spreading the virus. With COVID-19's challenging global outreach, international reconsideration of handwashing frequency and technique is more significant than ever before. Hence, an attempt has been made through this review article to gather refocus on the issue of poor hand hygiene in the WHO Region of South East Asia at the time when about half of the schools and households along with one fourth of health care centers here lack a dedicated handwashing facility. Ignorance in handwashing is one of the main and frequent modes of transmission of COVID-19. So under such pandemic situation, people should understand that handwashing can be the difference between life and death.

As per WHO/UNICEF JMP 2020, facilities for handwashing in households, schools, and health care centers in the countries of South East Asia, there are 4 in every 10 households (Table 3 and Bar 1) not having any dedicated place for washing hands with soap and water on premises. There are $50 \%$ schools without handwashing facilities with soap and water for students. About 1 in every 4 hospitals in South East Asia lacks a functional handwashing facility with soap and water/sanitizer.

Here in South East Asia, washing hands with soap and water receive too low a priority (Table 4 and Bar 2) at homes and in schools despite the availability of basic water service.

The data shows that $92 \%$ of those households that have good water facility do not consider handwashing to be of significance. Only 59\% of them give priority to handwashing and thus can be considered to have access to basic hygiene. It is a serious concern particularly when one third of the total global COVID-19 positive cases are getting added daily in South East Asian Countries these days. Only 69\% schools are having at least basic water supply where only $52 \%$ of them have good handwashing facilities at their disposal.
Table 3 and Bar 1: Percentage of households, schools, or hospitals without basic handwashing facilities

\begin{tabular}{ll}
\hline Places & Percentage of places lacking handwashing facility \\
\hline Households & 40 \\
Schools & 50 \\
Hospitals & 25 \\
\hline
\end{tabular}

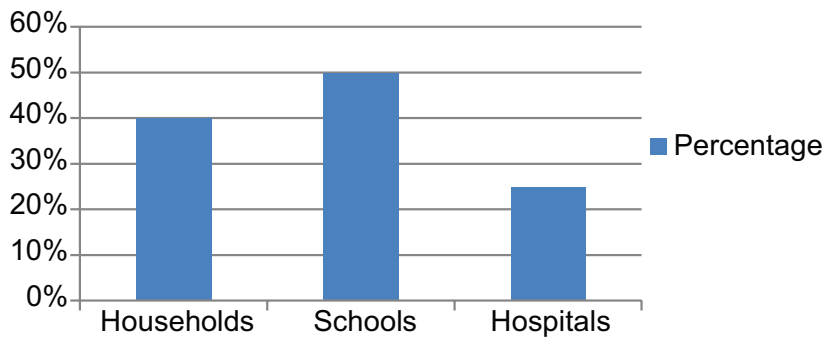

Country wise access to basic hygiene services in South-East Asia, for households (2017), Schools, and Health Care Facilities (2016) (Table 5 and Bar 3) below shows that availability of basic water service does not seem to be a limiting factor for having a handwashing facility with soap and water at home. Data show that Maldives is topping the list where $99 \%$ of household, schools, or health care centers are there with water facility and $96 \%$ of them have access to basic handwashing facility. In India, $93 \%$ have water facility but only $60 \%$ get handwashing facility. Nepal, Bangladesh, and Timor-Leste show the number of below $50 \%$ for access to basic hygiene.

When population without basic hygiene (Table 6 and Bar 4), of the different South East Asian Countries is seen, India, the second most populated country in the world, has about 540 million such people followed by Bangladesh and Indonesia. Myanmar shows only 11 million such people.

\section{DISCUSSION}

COVID-19 is a highly infectious disease caused by SARS COV-2. Hand hygiene can reduce the spread of such pathogenic microorganisms. Owing to the soothing fact that vaccines are currently being developed [24], other actions needed for reduction of SARS CoV-2 transmission are gaining significance [25] and they being 
Table 4 and Bar 2: Access to basic WASH services in South-East Asia, 2017 (households) and 2016 (schools and hospitals) * Regional estimates are only available for hospitals and not for all health care facilities

\begin{tabular}{lll}
\hline Places & At least basic water (\% age) & Basic hygiene (\% age) \\
\hline Households & 92 & 59 \\
Schools & 69 & 52 \\
Hospitals & 92 & 76 \\
\hline
\end{tabular}

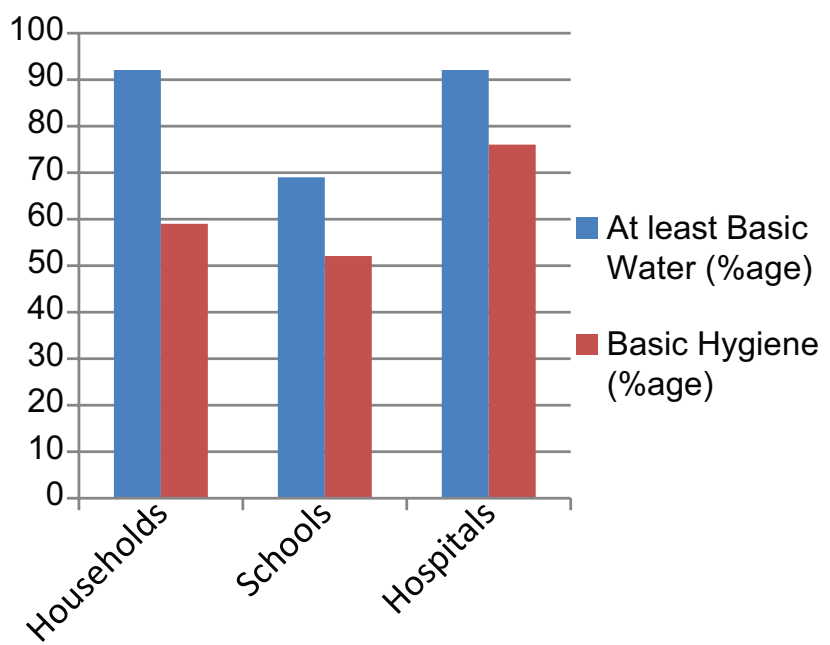

Table 5 and Bar 3: Access to basic hygiene services for countries in South-East Asia, 2017 (households) and 2016 (schools and health care facilities) for South-East Asian countries with available nationally representative data

\begin{tabular}{lll}
\hline Country & At least basic water & Basic hygiene \\
\hline Maldives & 99 & 96 \\
Thailand & 100 & 84 \\
Myanmar & 82 & 79 \\
Indonesia & 89 & 64 \\
India & 93 & 60 \\
Nepal & 89 & 48 \\
Bangladesh & 97 & 35 \\
Timor-Leste & 78 & 28 \\
\hline
\end{tabular}

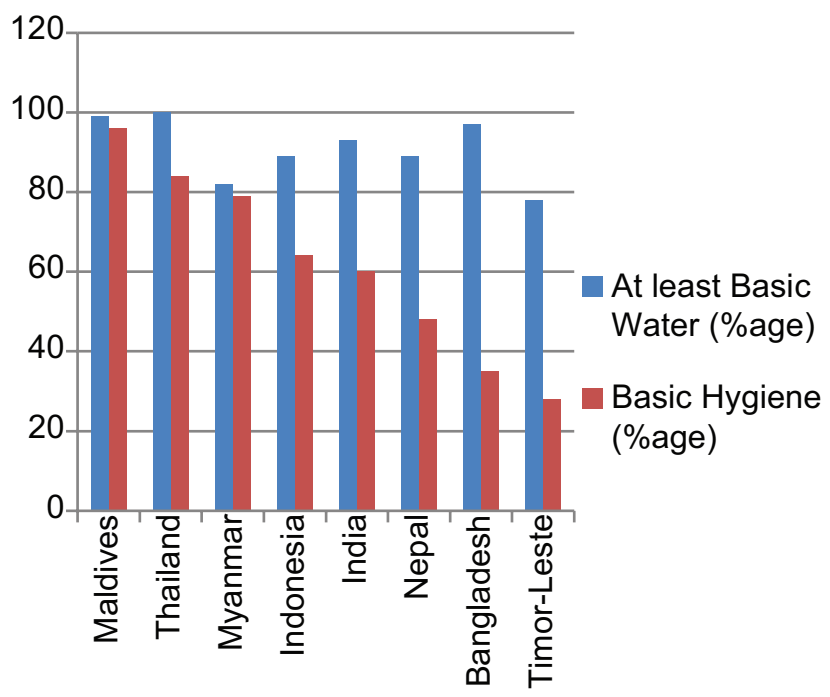

Table 6 and Bar 4: Distribution of population without basic hygiene at the household, South-East Asian countries, 2017

\begin{tabular}{ll}
\hline Country & Population (in Millions) \\
\hline India & 542 \\
Bangladesh & 107 \\
Indonesia & 94 \\
Nepal & 15 \\
Thailand & 11 \\
Myanmar & 11 \\
Rest of the Region & 15 \\
\hline
\end{tabular}

Population (in Millions)

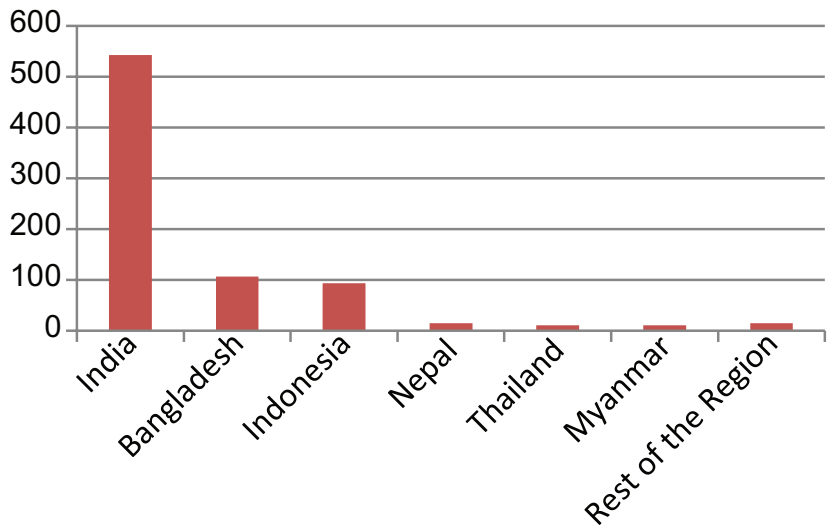

recommended by major authorities. One of the important of these actions is maintaining proper hand hygiene. It was indicated by the WHO as the first action that should be taken by individuals to protect themselves and others, by washing hands frequently with water and soap for $20 \mathrm{~s}$ at least or using hand-sanitizing gel [26]. Similarly, the UNICEF released a statement that, during a global pandemic, one of the cheapest, easiest, and most important ways to prevent the spread of a virus is to wash hands frequently with soap and water [27]. Likewise, national organizations, such as the Centers for Disease Control and Prevention of United States of America, emphasized that during the COVID-19 pandemic keeping hands clean is especially important to help prevent the virus from spreading [28]. Alcohol-containing handrub solutions are an efficacious alternative to handwashing with soap and water [29].

Although, globally, the numbers of people lacking access to handwashing facilities with soap and water are large, there have been substantial improvements in many regions of the world (Table 7) [30]. However, if we consider South East Asia, there are still a considerable number of people as compared to others that lack access to handwashing with soap and water. In the presence of global COVID-19 pandemic, we cannot ignore the figures howsoever small they are.

Most of the countries here in South East Asia are vulnerable to a mass outbreak due to their high population density in cities proving challenging to maintain social distancing, poor hygiene, and lower (health) literacy rate. In addition, some COVID-19 cases remain asymptomatic making it more difficult to access the severity of situation [31].

Washing of hands with soap and staying at home are all very well for the privileged who can afford to do so; however, for the poor with 5-6 or more members living in one room within slums such as in Bangladesh and India getting irregular water supply, communal latrines, in some of the dirtiest and densest places in South East Asia, such situation needs immediate reconsideration [32]. 
Table 7: Estimated percentage of population without access to handwashing with soap and water globally and by GBD region, 1990 and 2019. Estimates were based upon input survey data inputs into a spatiotemporal Gaussian process regression model with access to piped water and the sociodemographic index as model covariates

\begin{tabular}{lll}
\hline Region & $\begin{array}{l}\text { Percentage of population without access. } \\
\mathbf{1 9 9 0}(\mathbf{9 5 \%} \mathbf{U I})\end{array}$ & $\begin{array}{l}\text { Percentage of population without } \\
\text { access, 2019 (95\% }\end{array}$ \\
\hline Global & $33.6(3 \mathrm{~L} 5,35.6)$ & $26.1(24.7,27.7)$ \\
East Asia & $26.1(24.2,28.1)$ & $7.7(6.9,8.4)$ \\
Southeast Asia & $28.6(24.1,33.5)$ & $16.6(14.1,19.5)$ \\
Oceania & $63.3(56.0,69.4)$ & $56.6(52.5,60.5)$ \\
Central Asia & $13.6(11.3,16.4)$ & $7.8(6.5,9.4)$ \\
Central Europe & $5,5(4.5,6.9)$ & $2.8(2.3,3.4)$ \\
Eastern Europe & $6.4(4.6,8,5)$ & $3,9(2.7,5.3)$ \\
High-income Asia Pacific & $1,4(1.0,2.0)$ & $1.0(0.6,1.4)$ \\
Australasia & $1.5(0.9,2.1)$ & $1.0(0.7,1.6)$ \\
Western Europe & $1.3(1.1,1.6)$ & $0.9(0.8,1.1)$ \\
Southern Latin America & $5.4(3.6,19)$ & $1.5(1.0,2.1)$ \\
High-income North America & $0.6(0.4,0.9)$ & $0.4(0.3,0.5)$ \\
Caribbean & $35.4(31.6,39,5)$ & $34.1(31.1,36.8)$ \\
Andean Latin America & $23.8(18.5,29,8)$ & $12.9(9.6,16.8)$ \\
Central Latin America & $18.6(15.2,23.0)$ & $10,6(8.8,12.6)$ \\
Tropical Latin America & $29.9(21.0,40.5)$ & $13,8(9.1,20.5)$ \\
North Africa and Middle East & $33.0(29.9,36.3)$ & $21.1(19.8,22.6)$ \\
South Asia & $59.5(50.3,68.7)$ & $37.2(31.2,43.5)$ \\
Central sub-Saharan Africa & $89.7(86.9,92.0)$ & $81.7(79.1,84.1)$ \\
Eastern sub-Saharan Africa & $92.4(90.9,93.6)$ & $83.6(82.3,84.9)$ \\
Southern sub-Saharan Africa & $64.8(56.1,72.6)$ & $51,2(45.7,56.7)$ \\
Western sub-Saharan Africa & $90.7(88.4,92,7)$ & $85,5(83.5,87.3)$ \\
\hline
\end{tabular}

Now: Burden of diseases injuries, and risk factors study; Ui: Uncertainty interval.

Many of the measures like hand hygiene effective to contain transmission and mitigate the epidemic are difficult or impossible to institute in poorer low and middle income countries or upper middle income countries such as Bangladesh, Nepal, Sri Lanka, where for example running water may not be easily accessed or people live in very crowded conditions [33]

Re-opening of schools in the context of COVID is complex. Only half of schools globally have access to water and soap for handwashing, and levels are further low in low and middle income countries [34].

Proper hand hygiene is practiced more in USA and Europe than in South Asian countries. This is expected because of the difference in the socioeconomic conditions of these nations [35]

India is one of the nations in South East Asia. It is the $2^{\text {nd }}$ largest populated country in the world, where the healthcare system is severely suffering due to lack of infrastructure ( 0.7 hospital beds $/ 1000$ people), medical equipments, and doctors (doctor: Population ratio is 1: 1800 instead of 1:1000) [36].

Unfortunately, about 70,000 daily COVID-19 cases are reported here these days. The country runs a nationwide mega program of Swachh Bharat Mission. However, the focus on handwashing was not included in this large Swachh Bharat Mission, or Clean India Programme, launched in 2014.

India's proportion of households without soap or water is lower than the $71.4 \%$ of people in Bangladesh or $52.9 \%$ in Nepal lacking such amenities. However, Indian households fared worse than Myanmar (16.4\%) during the same period. When the data are broken down, we found that $20 \%$ of households in urban areas, where access to running water is more common, had no handwashing facilities, compared to $51 \%$ in rural areas. Regional disparities are even wider: ranging from below $10 \%$ in Delhi to above $60 \%$ in the entire state of Odisha. The research also shows that only $4 \%$ of the richest households did not have handwashing facilities, compared to $80 \%$ of the poorest households. The worst levels of hand hygiene were observed in houses with an absence of toilet facilities (64\%) or in illiterate families (68\%) [37]

The basic mitigation process for LMIC country like Bangladesh is quarantine, social distancing, and personal hygiene such as WASH and cough etiquette for COVID19. Deficiency is observed in each of these components [38].

The case of Indonesia is not so much different. As many as 33.4 million people still lack access to clean water [39]. The low personal hygiene and poor sanitation indicators in Indonesia are a challenge in controlling COVID19 in Indonesia [40]. Basic Health Research data mentioned that $50.2 \%$ practice improper handwashing [41]. The behavior of cleaning hands with soap and running water has been socialized through electronic media and print media. The School Health Unit program also promotes handwashing with soap but is still not optimal. Studies in Indonesia found that handwashing behavior is influenced by the presence and distance of handwashing facilities, interpersonal influence, the desire to smell good, washing hands when feeling dirty [42]. This behavior is closely related to COVID19's control efforts. Therefore, hygiene and sanitation factors need to get the attention of policymakers in controlling COVID-19.

\section{CONCLUSION}

COVID-19 is a highly contagious disease transmitted mainly through two routes, that is, respiratory and poor hygiene. Nearly one third of the global new COVID-19 positive cases and around one fifth of the total new deaths are reported from the WHO Region of South East Asia these days. Handwashing has been recommended by WHO as an important strategy for prevention of COVID-19 transmission in households, schools, and other community places. The availability of a basic handwashing device is a prerequisite for basic hygiene facilities on premises. However, about half of the households, schools and about one fourth of the heath institutions in South East Asia lack, basic handwashing facility provided with soap and water. Hence, the factor of hand hygiene and sanitation needs reconsideration in South East Asia because well managed water, sanitation, and hygiene services are critical for prevention of various diseases and safety of human health during infectious disease outbreaks.

\section{REFERENCES}

1. Beiu C, Mihai M, Popa L, Cima L, Popescu MN. Frequent hand washing for COVID-19 prevention can cause hand dermatitis: Management tips. Cureus 2020;12:e7506. 
2. Głabska D, Skolmowska D, Guzek D. Population-based study of the influence of the COVID-19 pandemic on hand hygiene behaviors-polish adolescents' COVID-19 experience (PLACE-19) study. Sustainability 2020;12:4930.

3. Singhal T. A review of coronavirus disease-2019 (COVID-19). Indian J Pediatr 2020;87:281-6.

4. World Health Organization. Modes of Transmission of Virus Causing COVID-19: Implications for IPC Precaution Recommendations. Geneva: World Health Organization; 2020

5. Chan JF, Yuan S, Kok KH, To KK, Chu H, Yang J, et al. A familial cluster of pneumonia associated with the 2019 novel coronavirus indicating person-to-person transmission: A study of a family cluster. Lancet 2020;395:514-23.

6. Ong SW, Tan YK, Chia PY, Lee TH, Ng OT, Wong MS, et al. Air, surface environmental, and personal protective equipment contamination by severe acute respiratory syndrome coronavirus 2 (SARS-CoV2) from a symptomatic patient. JAMA 2020;323:1610-2.

7. Wu Y, Chen C, Chan Y. The outbreak of COVID-19: An overview. J Chin Med Assoc 2020;83:217-20.

8. Doremalen NV, Bushmaker T, Morris H, Holbrook MG, Gamble A Williamson BN, et al. Aerosol and surface stability of SARS-CoV-2 as compared with SARS-CoV-1. N Engl J Med 2020;382:1564-7.

9. Bai Y, Yao L, Wei T, Tian F, Jin DY, Chen L, et al. Presumed asymptomatic carrier transmission of COVID 19. N Engl J Med 2020;323:1406-7.

10. Lirong Z, Feng R, Mingxing H, Lijun L, Huitao H, Zhongsi H, et al. SARS-CoV-2 viral load in upper respiratory specimens of infected patients. N Engl J Med 2020;382:1177-9.

11. Rothe C, Schunk M, Sothmann P, Bretzel G, Froeschl G, Wallrauch C, et al. Transmission of 2019-nCOV infection from an asymptomatic contact in Germany. N Engl J Med 2020;382:970-1.

12. World Health Organization. Improve Hand Hygiene Practices Widely to Help Prevent the Transmission of the COVID-19. Geneva: World Health Organization; 2020.

13. Roberts L, Jorm L, Patel M, Smith W, Douglas RM, McGilchrist C. Effect of infection control measures on the frequency of diarrheal episodes in child care: A randomized, controlled trial. Pediatrics 2000;105:743-6.

14. Bowen A, Ma H, Jianming O, Billhimer W, Long $\mathrm{T}$, Mintz E, et al A cluster-randomized controlled trial evaluating the effect of a hand washing-promotion program in Chinese primary schools. Am J Trop Med Hyg 2007;76:1166-73.

15. Ejemot RI, Ehiri JE, Meremikwu MM, Critchley JA. Hand washing for preventing diarrhoea. Cochrane Database Syst Rev 2012;1:CD004265.

16. Kumar S, Loughnan L, Luyendijk R, Hernandez O, Weinger M, Arnold F, et al. Handwashing in 51 countries: Analysis of proxy measures of handwashing behavior in multiple indicator cluster surveys and demographic and health surveys, 2010-2013. Am J Trop Med Hyg 2017;97:447-59.

17. Mukherjee S. Factors Influencing Access to Basic Handwashing Facilities in Developing Countries (No. 99607). Germany: University Library of Munich; 2020.

18. UNICEF. Water and Sanitation: The Ripple Effect. United States: UNICEF; 2017. p. 1-16. Available from: https://www.unicef.org/wash/ files/Climate change WASH Brief.pdf. [Last accessed on 2020 Apr 12].

19. Geall S, Al'Afghani MM. The right to safe water in Southeast Asia. Available from: https://www.cdn.chinadialogue.net/content/ uploads/2020/07/07131910/The-right-to-safe-water-in-SoutheastAsia_2020-01_28_web.pdf.

20. COVID-19: Water and Sanitation-related Information. Available from: https://www.unwater.org/covid-19-water-and-sanitation-relatedinformation.

21. WHO/UNICEF JMP (WHO/UNICEF Joint Monitoring Programme for Water Supply, Sanitation and Hygiene). 2020. Available from: https:// www.washdata.org. [Last accessed on 2020 Mar 25].

22. WHO, UNICEF. 2017. Progresson Drinking Water, Sanitationand
Hygiene. 2017 Update and SDG Baselines. Available from: https:// www.unicef.org/publications/files/Progress_on_Drinking_Water Sanitation and Hygiene 2017.pdf. [Last accessed on 2020 May 11].

23. WHO/UNICEFJMP (WHO/UNICEF Joint Monitoring Programme for Water Supply, Sanitationand Hygiene); 2020. Available from: https:// www.washdata.org. [Last accessed 2020 Mar 25].

24. Corey BL, Mascola JR, Fauci AS, Collins FS. A strategic approach to COVID-19 vaccine R\&D. Science 2020;368:948-50.

25. Cirrincione L, Plescia F, Ledda C, Rapisarda V, Martorana D, Moldovan RE, et al. COVID-19 pandemic: Prevention and protection measures to be adopted at the workplace. Sustainability 2020;12:3603.

26. World Health Organization. WHO Announces COVID-19 Outbreak a Pandemic. Available from: http://www.euro.who.int/en/health-topics/ health-emergencies/coronavirus-covid-19/news/news/2020/3/whoannounces-covid-19-outbreak-a-pandemic. [Last accessed on 2020 May 14].

27. United Nations International Children's Emergency Fund. Everything You Need to Know about Washing Your Hands to Protect Against Coronavirus (COVID-19). Available from: https://www.unicef org/coronavirus/everything-you-need-know-about-washingyourhandsprotect-against-coronavirus-covid-19. [Last accessed on 2020 May 14]

28. Centers for Disease Control and Prevention. When and How to Wash Your Hands. Available from: https://www.cdc.gov/handwashing/whenhow-handwashing.html. [Last accessed on 2020 May 14].

29. Kampf G. Efficacy of ethanol against viruses in hand disinfection. J Hosp Infect 2018;98:331-8.

30. Brauer M, Zhao JT, Bennitt FB, Stanaway JD. Global access to handwashing: Implications for COVID-19 control in low-income countries. Environ Health Perspect 2020;128:057005.

31. Asim M, Sathian B, van Teijlingen E, Mekkodathil A, Subramanya SH, Simkhada P. COVID-19 pandemic: Public health implications in Nepal. Nepal J Epidemiol 2020;10:817-20.

32. Rashid SF, Theobald S, Ozano K. Towards a socially just model: Balancing hunger and response to the COVID-19 pandemic in Bangladesh. BMJ Global Health 2020;5:e002715.

33. Zar HJ, Dawa J, Fischer GB, Castro-Rodriguez JA. Challenges of COVID-19 in children in low-and middle-income countries. Paediatr Respir Rev 2020;35:70-4.

34. World Health Organization. United Nations Children's Fund (UNICEF) Global Baseline Report 2018. Geneva: World Health Organization; 2018

35. Paul A, Chatterjee S, Bairagi N. Prediction on Covid-19 epidemic for different countries: focusing on South Asia under various precautionary measures. MedRxiv 2020; Jan 1.

36. Paital B, Das K, Parida SK. Inter nation social lockdown versus medical care against COVID-19, a mild environmental insight with specia reference to India. Sci Total Environ 2020;728:138914

37. India and Coronavirus: Lack of Access to Handwashing Facilities Among Poor Makes Fight Even Harder. Available from: https://www.horizon. documentation.ird.fr/exl-doc/pleins_textes/divers20-05/010077646. pdf. [Last accessed on $2020 \mathrm{Apr}$ 01].

38. Amin MR, Sharif M, Faiz MA. The first family cluster of COVID-19 in Bangladesh enigma in developing country. J Bangladesh Coll Physicians Surg 2020;38:141-4.

39. Patunru AA. Access to safe drinking water and sanitation in Indonesia. Asia Pac Pol Stud 2015;2:234-44

40. Purnama SG, Susanna D. Hygiene and sanitation challenge for COVID-19 prevention in Indonesia. Kesmas Natl Public Health J 2020;1:6-13.

41. Kementerian Kesehatan Republik Indonesia. Riset Kesehatan Dasar 2018. Jakarta: Kementerian Kesehatan Republik Indonesia; 2018.

42. Hirai M, Graham JP, Mattson KD, Kelsey A, Mukherji S, Cronin AA Exploring determinants of handwashing with soap in Indonesia: A quantitative analysis. Int J Environ Res Public Health 2016;13:868. 